\title{
Automobile Thermoelectric Exhaust Generator
}

\author{
Param Gupta $^{1}$, Hemant Sharma ${ }^{2}$ and Jatin Bhalla ${ }^{3}$ \\ Chitkara University Punjab, India \\ 1paramgupta1996@gmail.com, ${ }^{2}$ hemantsharma1995@gmail.com, \\ jatin.bhalla93@gmail.com
}

\begin{abstract}
This paper gives an overview on the use of thermoelectric materials to generate electricity through the waste heat of the exhaust gases of a vehicle. Various thermoelectric modules will be attached to the end of the exhaust of the vehicle. The exhaust pipe will act as the hot end. Fins will be used to provide a cold end for the module. By using Seebeck effect of thermoelectricity, a voltage difference will be generated which will be used to charge batteries. The batteries will be automatically charged when the vehicle runs and then, that power, generated free of cost, can be utilized further.
\end{abstract}

Keywords: Thermoelectrics, Automobile exhaust generators, Seebeck effect

\section{Introduction}

Nowadays, our country and by large, the whole world is going through an energy crisis. The cost of energy is rising day by day. Also, the availability of energy, mainly in the form of electricity, is a huge problem in some cases. Thus, devising a way to get energy at a cheap rate is very important.

Recently, the electric load of a vehicle has been increasing due to the need of more and more auxiliary systems, such as the AC, parking lights, sensors, music system, etc., to provide more comfort. For this increase in demand, bigger and heavier alternators have to be used to get the required output to be consumed by the ever increasing number of auxiliary systems. These alternators consume around $2 \%$ of the shaft power available to us and thus, reducing the efficiency of the engine. Normally, in internal combustion engines; the efficiency of the engine is around 30\%, roughly $30 \%$ is lost as exhaust gas, $30 \%$ in cooling water and the rest $10 \%$ are unaccountable losses. If this heat emitted from the exhaust is harnessed, it can provide an alternate source of electricity. So, with the help of thermoelectric materials, we can use the heat lost as waste through the exhaust and increase the efficiency of the engine.

\section{Solutions Proposed}

The paper presents a solution for concerned problems. Normally, a lot of heat is lost through the exhaust gases. Here, we are using that waste heat and converting that heat energy to electrical energy with the help of thermoelectric power generators. These generators use Seebeck effect to produce electricity when a temperature gradient is present across two ends. Now, when the vehicle runs, a battery will be charged and this can be further used to run different electrical appliances. This power generated will be free of cost to the user.

This type of technology can be very useful in rural areas where electricity is not available round the clock. Also, the air conditioning system in cars use the power produced by the engine to run and thus, reduce the amount of power available to the axle. 
In this case, the air conditioner can be run using the energy produced through this generator. This will help to get power to the axle.

\section{System Architecture and Design}

The device, an extension on the exhaust pipe, is attached to exhaust of the automotive vehicle towards it end. Therefore, the gases that are emitted from the exhaust transfer their heat through the exhaust pipe to the ATEG which consists of thermoelectric modules embedded into the structure at the upper end, parallel to the flow of the gas. This flow of exhaust gas helps the module to develop the hot end. An air cooling system, consisting of fins and a rectangular cavity, are used to reduce the temperature of the upper end and provide the cool sides to the two modules. Thus, a temperature gradient is provided for the modules to work.Using the Seebeck effect of thermoelectric substances, electricity is generated. The electric power thus generated by the modules is then transferred to a battery and it gets charged.

\subsection{Aluminum Block}

A $125 \mathrm{mmX} 125 \mathrm{mmX} 150 \mathrm{~mm}$ block of Aluminum was obtained (as shown in Figure 1) and then different types of processes were done on it to get the required shape.

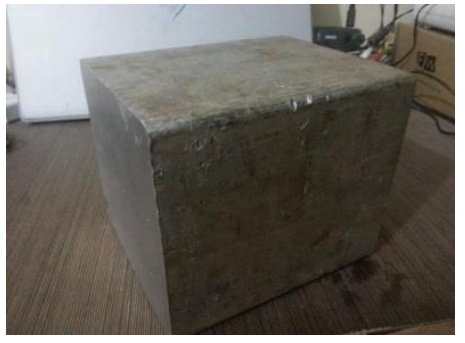

Figure 1. Aluminium Block

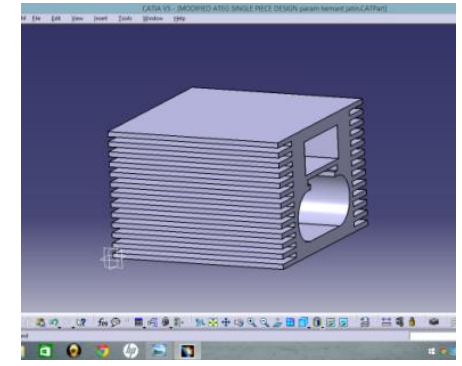

Figure 2. Fins Structure

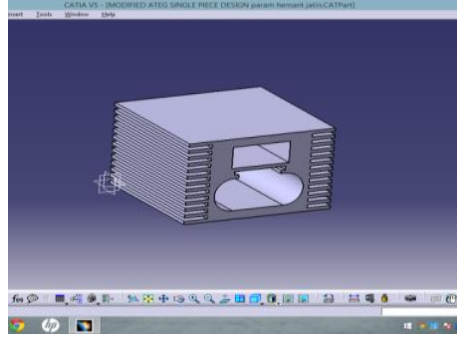

Figure 3. Front Face of the Structure

\subsection{Fins}

Rectangular fins are used in this design. These are made on the above mentioned Aluminum block by machining process. The fins are made on two sides of the block, i.e. left and the right side. Design of Fins is simulated using the CATIA software. Refer Figure 2 for this.

\subsection{Exhaust Hole}

The hole is provided in the above said structure for the exhaust . Two different types of cross-sections of exhaust hole are shown in Figure 3 and Figure 4. Figure 3 represents the back side of the exhaust hole of ATEG and Figure 4 represents the front side. The front end, has an elongated hole cross-section, whereas, the back side has a circular crosssection, when seen from the rear end of the car. In the rear end of the ATEG, the exhaust pipe of the car is inserted. The exhaust hole helps to attach the ATEG module to almost any vehicle. 


\subsection{Rectangular Air Cavity}

A rectangular cavity is provided below the exhaust hole. It runs along the whole length of the designed component. Its work is to further increase the amount of cooling that takes place. (Refer Figure 4)

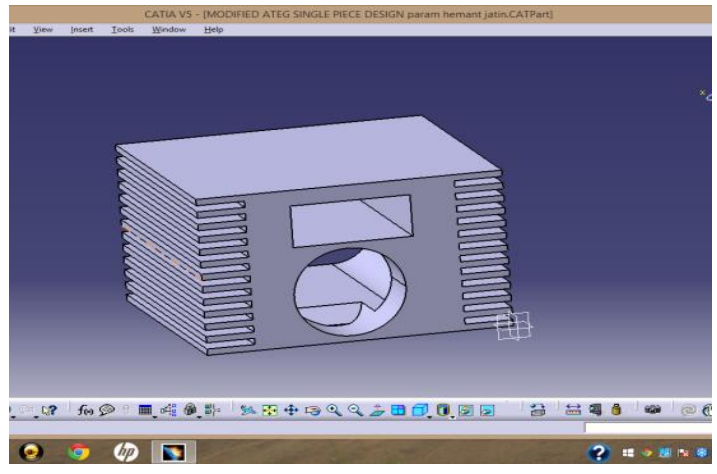

Figure 4. Rectangular Cavity in

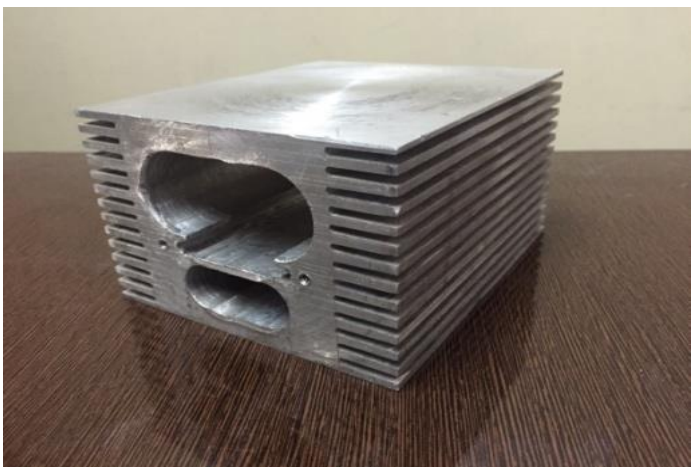

Figure 5. Real Time Structure Structure

\section{5 . Thermoelectric Modules}

In this design, two thermoelectric modules to convert heat energy into electrical energy. These modules work on Seebeck effect. They are fitted in the lower part of the exhaust hole. The thermoelectric module used here isTEP-1264-1-5, which are Bi-Te based and work at a temperature upto $400^{\circ} \mathrm{C}$. The module has high thermal conductivity Graphite sheets on both sides of the ceramic plates to provide low contact thermal resistance. The module produces DC voltage corresponding to the temperature gradient. Figure 6 shows the real time image of Thermoelectric modules.Figure 7 and Figure 8 show the performance curves of the module.

Specifications of the module:

Size: $40 \mathrm{~mm}$ X $40 \mathrm{~mm}$

Open circuit voltage: $9.4 \mathrm{~V}$

Matched load output resistance: $2.8 \Omega$

Matched load output voltage: $4.7 \mathrm{~V}$

Matched load output current: 1.56Amps

Matched load output power: $7.3 \mathrm{~W}$

Heat flow through the module: About $133 \mathrm{~W}$

Heat flux: About $8.3 \mathrm{~W} / \mathrm{cm}^{2}$

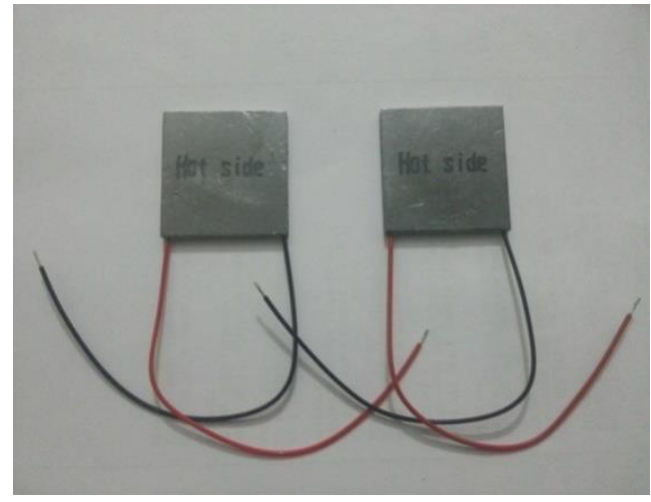

Figure 6. Thermoelectric Modules 


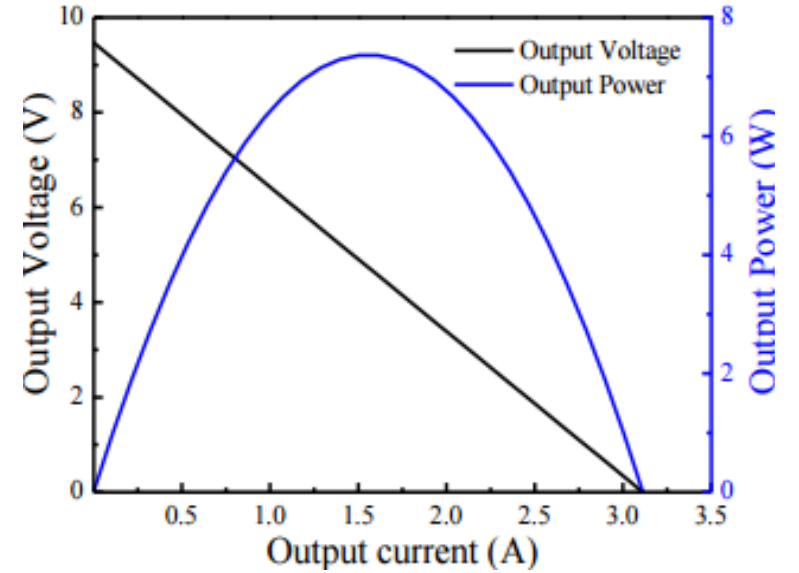

Figure 7. Voltage vs. Current curve

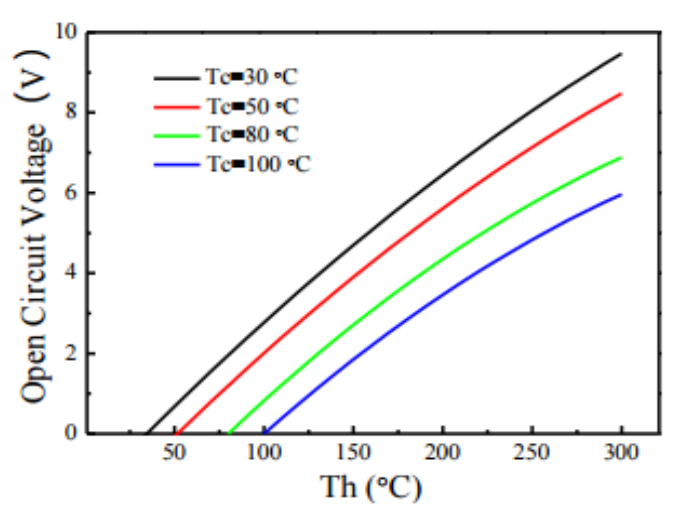

Figure 8. Voltage vs. Temperature curve

\subsection{Battery}

Battery is like a fuel tank for the electric system and requires refillingby the means of charging. A $12 \mathrm{~V}$ battery was used to store the energy being produced by the thermoelectric modules in the process. The energy stored in it can be used further.

\section{Circuit Design}

A circuit was designed for the ATEG which would help us in getting up electrical power from the system. This circuit stabilizes the wavy nature of the output voltage and we get a constant DC voltage which is then used further. Figure 9 shows the Circuit diagram of the proposed system and Figure 10 shows the real time circuit.

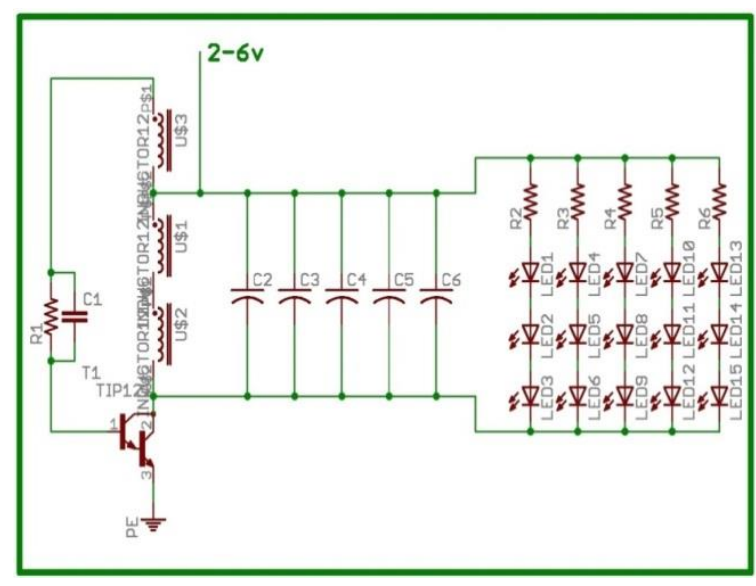

Figure 9. Circuit Diagram

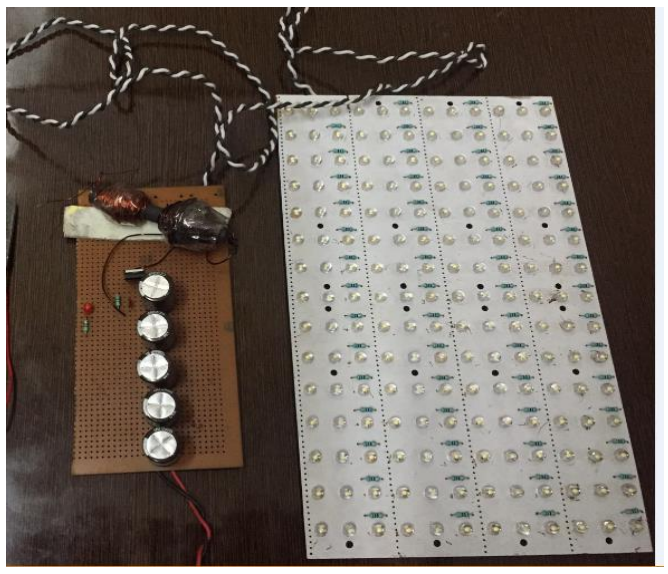

Figure 10. Real Time Circuit

\section{Performance Analysis of the Proposed System}

The observations of the temperature of the gases coming out of the end of the exhaust pipe of different vehicles were taken at various RPMs to determine and estimate the average temperature of the gases coming out of the exhaust at different RPMs. This was 
done to have a better idea of the temperature difference that can be generated between the two faces of the thermoelectric modules.

A. HYUNDAI i20 (1396CC Diesel Car,2012 Model)

\begin{tabular}{ccc}
\hline S.Ne. & RPM & TEMP $\left({ }^{\circ} \mathrm{C}\right)$ \\
\hline 1. & 1000 & 84 \\
\hline 2. & 1500 & 105 \\
\hline 3. & 2000 & 113 \\
\hline 4. & 2500 & 120 \\
\hline 5. & 3000 & 148 \\
\hline
\end{tabular}

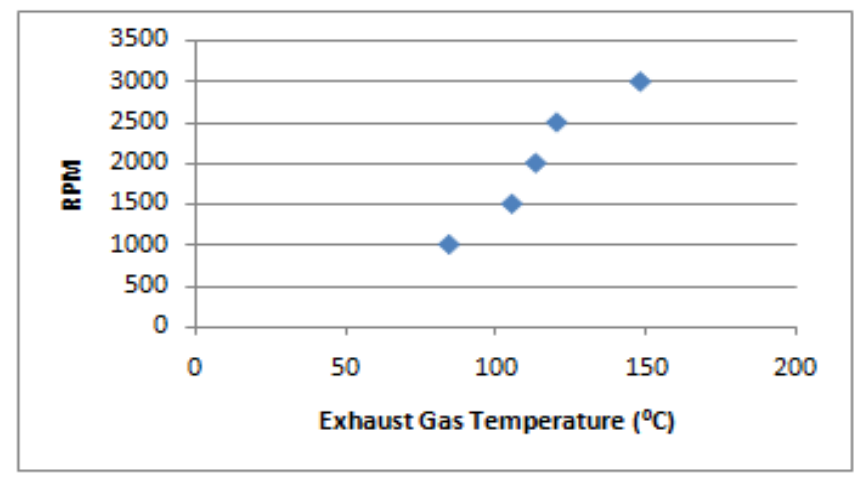

\section{Graph 1. RPM vs. Exhaust Gas Temperature for HYUNDAI}

B. Maruti Suzuki Swift VXI(1198CC Petrol, 2007 Model)

\begin{tabular}{ccc}
\hline S.No. & RPM & TEMP $\left({ }^{\circ} \mathrm{C}\right)$ \\
\hline 1. & 1000 & 86 \\
\hline 2. & 1500 & 108 \\
\hline 3. & 2000 & 127 \\
\hline 4. & 2500 & 144 \\
\hline 5. & 3000 & 151 \\
\hline
\end{tabular}

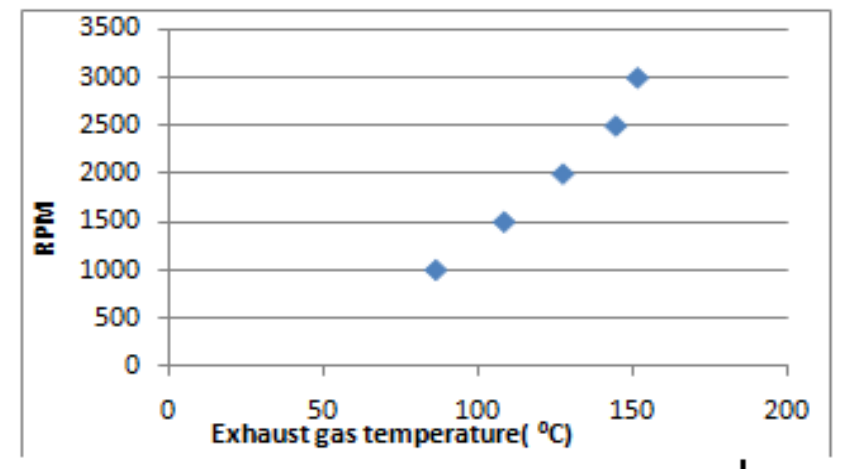

\section{Graph 2. RPM vs. Exhaust Gas Temperature for Maruti Swift}

The ATEG was attached to the exhaust of the vehicle and its performance was analysed. The table below gives us an idea of the output of the system. Figure 11 shows the designed system attached to the exhaust of the car. Figure 12 shows the LED panel being illuminated by the output voltage produced by the ATEG designed.

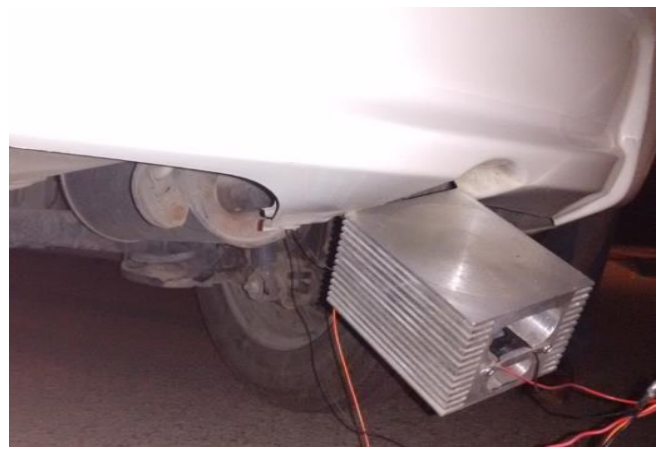

Figure 11. The ATEG Structure Attached to the Exhaust Pipe

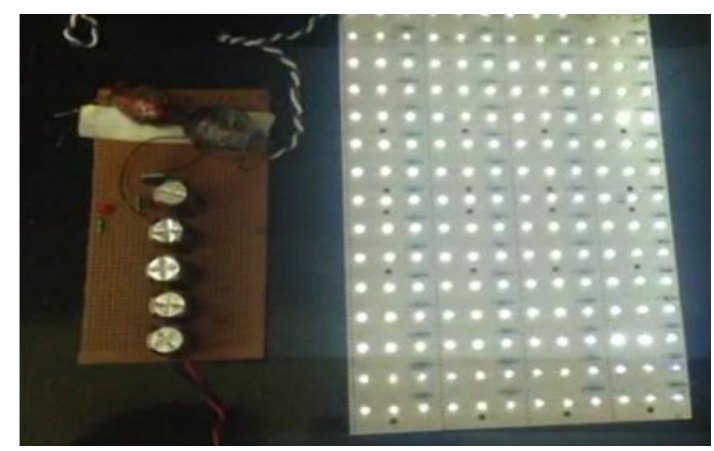

Figure 12. Illuminated Leds at High Voltage (4.8V) 


\begin{tabular}{cccc}
\hline S.No. & RPM & $\begin{array}{c}\text { TEMP } \\
\left({ }^{\circ} \mathbf{C}\right)\end{array}$ & $\begin{array}{c}\text { O/P } \\
\text { VOL. } \\
\text { (V) }\end{array}$ \\
\hline l. & 1000 & 86 & 2.3 \\
\hline 2. & 1500 & 108 & 3.1 \\
3. & 2000 & 127 & 3.9 \\
\hline 4. & 2500 & 144 & 4.8 \\
\hline
\end{tabular}

\section{Voltage -Temperature Graph}

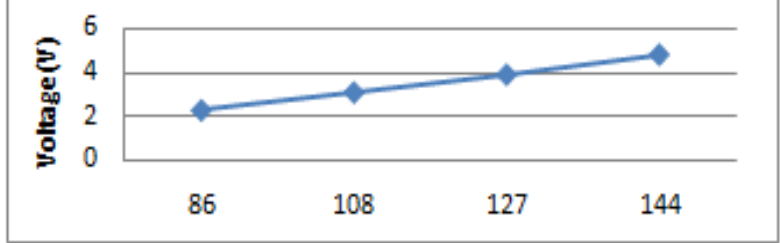

\section{Graph 3. Output Voltage vs. Exhaust Gas Temperature}

\section{Conclusion}

An ATEG system is designed successfully and it is both economical and environment friendly because it provides us which free energy using the heat which is lost through the exhaust. The amount of fuel used can be reduced using this system as it can run the auxiliary devices. Also, the battery can be charged to be used to run bulbs and other appliances at homes, etc. This system has a huge potential to be used in remote areas or in areas with low availability of electricity. This is a free source of energy and can be used in different kinds of vehicles.

\section{References}

[1] P. Ramade, P. Patil, M. Shelar, S. Chaudhary, S. Yadav and S. Trimbake, "Automobile Exhaust Thermo-Electric Generator Design \& Performance Analysis", International Journal of Emerging Technology and Advanced Engineering, vol. 4, Issue 5, (2014).

[2] K. Adhithya, R. Anand, G. Balaji and J. Harinarayanan, "Battery charging using thermoelectric generation module in automobiles", International Journal of Research in Engineering and Technology, vol. 4, Issue 2, (2015).

[3] Ved Roboticswww.vedrobotics.co.in.

[4] V. Ganesan, "Internal Combustion Engines", Third Edition, pub.-Tata McGraw-hill, (2009), pp 409-412

[5] R. K. Rajput, "Heat and Mass Transfer", Third Edition, pub.-TataMcGraw-hill, (2009).

[6] Wikipediahttps://en.wikipedia.org/wiki/Thermoelectric_generator.

[7] B. Bochentyn, J. Karczewski, T. Miruszewski and B. Kusz, "Structure and thermoelectric properties of Bi-Te alloys obtained by novel method of oxide substrates reduction", Journal of Alloys and Compounds, (2015).
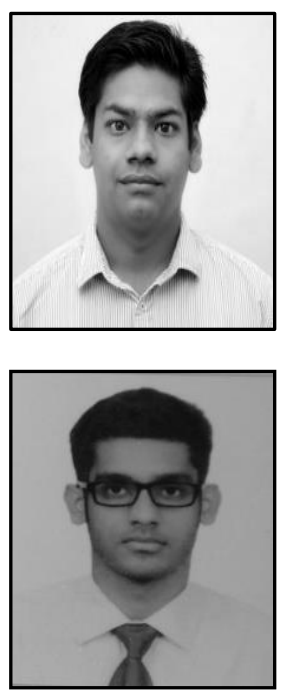

\section{Authors}

Param Gupta, he is currently pursuing his B.tech in mechanical engineering from Chitkara University. $\mathrm{He}$ has successfully organised the $5^{\text {th }}$ International Conference on Advances in Materials \& Manufacturing Technology. His field of interest includes production technology, machine design, strength of materials, etc, with proficiency in CNC Programming and CAD/CAM designing using CATIA.

Hemant Sharma, he is currently pursuing his B.Tech in Mechanical Engineering from Chitkara University, Punjab (India). $\mathrm{He}$ successfully organised the $5^{\text {th }}$ International Conference on Advances in Materials \& Manufacturing Technology. His fields of interest include Process Management, Mechatronics, Thermal Engineering and Production Technology, has proficiency in CAD/CAM designing using CATIA. 


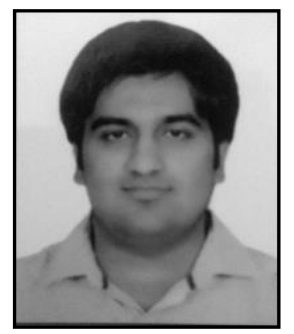

Jatin Bhalla, he is currently pursuing B.E mechanical engineering at Chitkara University. His fields of interest include Mechatronics, Machine Design, Thermal Engineering and Production Technology. 
International Journal of Control and Automation

Vol. 9, No. 10 (2016) 